\title{
Numerical Simulation of Impact Loads of Main Fan Blades in Gas Explosion
}

\author{
Jianliang Gao, ${ }^{1,2,3}$ Jingzhang Ren $\mathbb{D}^{\mathrm{D}},{ }^{3}$ Xuebo Zhang $\mathbb{D}^{1,},{ }^{1,2,3}$ Jiajia Liu $\mathbb{D}^{1,},{ }^{1,2,3}$ \\ and Chunxia Wang ${ }^{3}$ \\ ${ }^{1}$ The Collaborative Innovation Center of Coal Safety Production of Henan Province, Jiaozuo, China \\ ${ }^{2}$ State Key Laboratory Cultivation Base for Gas Geology and Gas Control, Jiaozuo, China \\ ${ }^{3}$ School of Safety Science and Engineering, Henan Polytechnic University, Jiaozuo, China \\ Correspondence should be addressed to Xuebo Zhang; zhxb@hpu.edu.cn
}

Received 27 August 2020; Revised 29 September 2020; Accepted 15 October 2020; Published 30 October 2020

Academic Editor: Qing Ma

Copyright (C) 2020 Jianliang Gao et al. This is an open access article distributed under the Creative Commons Attribution License, which permits unrestricted use, distribution, and reproduction in any medium, provided the original work is properly cited.

The shock wave generated by a severe gas explosion accident can damage the main fan, and the toxic and harmful gases in the well cannot be discharged in time, leading to the expansion of disaster accidents. Therefore, it is meaningful to study impact loads of main fan blades in gas explosion. In this paper, a full-scale three-dimensional numerical simulation model has been established based on No. 2 Yangchangwan Coal Mine in China. The propagation of shock wave in shaft and air tunnel and the dynamic process of main fan blade subjected to shock load when gas explosion of different volume occurs in heading face have been simulated. The overpressure on the blade at different times, the overpressure distribution on the blade, and the relationship between the overpressure and the explosion intensity have been obtained. The results showed that the time when the explosion shock wave reached, each blade of the wind turbine was basically the same, and the time when each blade reached, the maximum overpressure was basically the same. With the increase of gas explosion volume, occurrence time of overpressure and maximum overpressure time on the fan blade were shortened, and the time interval between them was also shortened. There is a little difference in the overpressure of each blade. Fan blade directly above the hub was subject to the highest overpressure, and fan blade directly below the hub was subject to the lowest overpressure. The overpressure of the maximum overpressure blade was $5.44 \%$ to $6.77 \%$ higher than that of the minimum overpressure blade. The distribution of overpressure on each fan blade was uneven, and the overpressures on blade edges were the lowest. The overpressure on the fan blades showed a corrugated distribution along the radial direction. There was $12.06 \%$ to $15.40 \%$ difference between the maximum and minimum overpressure section on the fan blade.

\section{Introduction}

The frequent occurrence of coal mine gas accidents, especially large gas explosions, poses a great threat to the safety of national property and people and seriously affects the healthy development of the coal industry. Gas explosions in laneway are a significant concern because of the extent to which they may harm personnel, equipment, and the production process [1]. Especially, explosion can turn deflagration into detonation in certain conditions [2-5], which would lead to much destruction. After the explosion in a coal mine, a large amount of toxic gases such as carbon monoxide will be generated. The explosion shock wave propagates along the return air route, which may cause the destruction of the main fan blades, resulting in airflow disorder of the entire ventilation system, and a large number of people in the underground will be poisoned or suffocated. Therefore, it is of great significance to study the propagation process of the blast wave in shaft and wind tunnel and the dynamic process of main fan blades under impact load when gas explosion occurs in the underground working face.

$\mathrm{Xu}$ et al. carried out the tunnel test research of gas explosion propagation in the mine [6]. Zhang et al. [7, 8] used numerical simulation method and explored the law of shock wave propagation through laneway bend and pressure distribution. The result showed that the attenuation of peak 
overpressure with distance did not obey the exponent law when the air shock wave goes through the laneway bend. The distribution of overpressure in the bending area was uneven. Hou et al. [9] studied the propagation and attenuation of shock waves in simplex turn roadway during gas explosion by numerical simulation and showed that the parameters of the shock wave in the turning roadway were attenuated during the propagation process. Jia et al. [10] carried out a study on the propagation characteristics of the gas explosion shock wave at the corner of the roadway. The result showed that when the shock wave went through the corner of the pipe, a complex flow field was generated. The greater the angle of the pipe bend and the greater the initial pressure of the shock wave, the more complex the reflection of the shock wave and the faster the shock wave attenuation. Lin and others simulated the tunnel structure and wall conditions of underground bifurcations, turns, and so on and conducted a systematic study on the propagation characteristics of flame waves and explosion waves in a gas explosion [11-13]. Zhu et al. [14] studied three angles of bending, and the results showed that the smaller the bending angle, the stronger the reflection of the shock wave, the stronger the turbulence caused, and the greater the peak overpressure formed. Blanchard et al. [15] studied the explosions in pipes containing baffles and a 90 bend. The results show that a 90 bend in a long tube has the ability to enhance flame speeds and overpressures and shorten the run-up distance to DDT to a varying degree for a number of gases. Ma et al. [16] studied the propagation characteristics of methane explosions in pipe networks using numerical simulation methods. The result showed that, in the parallel pipe network, the peak overpressure increased significantly at the intersection point, while the flame speed decreased at the junction. The above research shows that the current research methods can be divided into experimental methods and numerical simulation methods. Previous research has focused on the explosion of methane-air mixtures in small-scale vessels and their parameters [17-20], and the propagation of gas explosion shock waves in the tunnel has a scale effect $[21,22]$. Large-scale tests are not easy to carry out under the influence of conditions. Due to the improvement of computer's computing capabilities, the numerical simulation method has the characteristics of flexible settings, fewer consumables, and the ability to simulate wells and lanes of different sizes. At present, there are more studies on the propagation law of gas explosion shock waves in wells and lanes and little research on the shock load of main fans in gas explosions. FLUENT is now a popular commercial CFD software package in the international market. As long as it involves engineering issues, fluids, heat transfer, and chemical reactions can be explained [23]. In this paper, a full-scale three-dimensional numerical simulation model is established. The dynamic process of fan blades subjected to shock loads is simulated. Through simulation analysis, the change rule of the overpressure of the fan blades with time was the same. We determined the largest and smallest blades withstanding to overpressure and obtained the distribution characteristics of overpressure along the blade.

\section{Materials and Methods}

2.1. Mathematical Model. The blast wave generated after the gas explosion on the driving face propagates along the return airway to the shaft and then in the shaft to the wind tunnel and acts on the fan blades. During the entire propagation process, there are both flame propagation and pressure waves in the section near the explosion source. Generally, the shaft is far away from the driving face. When a gas explosion occurs at the underground face, the flame can only propagate a certain distance, the flame cannot reach the shaft. Therefore, only shock wave propagates in return air tunnel, shaft, and wind tunnel. The author numerically simulated the explosion process of the gas at the driving face and the propagation process of the shock wave from the driving face along the return air into vertical shaft. The distribution of the explosion shock wave on the shaft section of the vertical shaft and the law of its variation with time were obtained. Based on this, this paper took Yangchangwan No. 2 return air shaft as an example to study the propagation process of gas explosion shock wave from the driving face to the shaft, along the shaft to the air tunnel, main fans, and the dynamic process of fan blades bearing shock loads. Therefore, the governing equations followed by shock wave propagation include continuity equations and momentum equations. The turbulence model is selected from the widely used standard $k-\varepsilon$ model, and its expression as follows.

The continuity equation is written as follows:

$$
\frac{\partial \rho}{\partial t}+\frac{\partial}{\partial x_{i}}\left(\rho u_{i}\right)=0
$$

The momentum conservation equation is written as follows:

$$
\frac{\partial}{\partial x_{i}}\left(\rho u_{i} u_{j}\right)=-\frac{\partial p}{\partial x_{i}}+\frac{\partial}{\partial x_{i}}\left[\left(\mu+\mu_{t}\right)\left(\frac{\partial u_{j}}{\partial x_{i}}+\frac{\partial u_{i}}{\partial x_{j}}\right)\right] .
$$

The $k$ equation is written as follows:

$$
\frac{\partial(\rho k)}{\partial t}+\frac{\partial\left(\rho k u_{i}\right)}{\partial x_{i}}=\frac{\partial}{\partial x_{j}}\left[\left(\mu+\frac{\mu_{t}}{\sigma_{k}}\right)\right]+G_{k}-\rho \varepsilon
$$

The $\varepsilon$ equation is written as follows:

$$
\begin{aligned}
\frac{\partial(\rho \varepsilon)}{t}+\frac{\partial\left(\rho \varepsilon u_{i}\right)}{\partial x_{i}} & =\frac{\partial}{\partial x_{j}}\left[\left(\mu+\frac{\mu_{t}}{\sigma_{\varepsilon}}\right)\right]+C_{1 \varepsilon} \frac{\varepsilon}{k} G_{k}-C_{2 \varepsilon} \rho \frac{\varepsilon^{2}}{k}, \\
\mu_{t} & =\frac{C_{u} \rho k^{2}}{\varepsilon},
\end{aligned}
$$

where $x_{i}$ is the coordinates in the directions $x, y$, and $z, \mathrm{~m} ; u_{i}$ is the flow velocity $x, y$ and $z, \mathrm{~m} / \mathrm{s} ; \rho$ is roadway's gas density $\left(\mathrm{kg} / \mathrm{m}^{3}\right), P$ is effective turbulent pressure, $\mathrm{Pa} ; \mu$ is the laminar flow viscosity coefficient, Pa.s; $G_{k}$ is turbulent energy generation rate induced by time-averaged velocity gradient (\%); $\mu_{t}$ is the turbulent flow viscosity coefficient, $\mathrm{Pa} \cdot \mathrm{s} ; k$ is turbulent energy $(J), \varepsilon$ is the turbulent dissipation rate (\%) $C_{1 \varepsilon}$, $C_{2 \varepsilon}, C_{u}, \sigma_{k}$, and $\sigma_{\varepsilon}$ is empirical constant $\left(C_{1 \varepsilon}=1.44\right.$, $C_{2 \varepsilon}=1.92, C_{u}=0.09, \sigma_{\varepsilon}=1.3$, and $\left.\sigma_{k}=1.0\right)$. 
2.2. Physical Model. The driving working face of 020611 return air tunnel of Yangchangwan No. 2 well was $518 \mathrm{~m}$ away from the bottom of the return air shaft, the depth of the return air shaft was $556 \mathrm{~m}$, and the diameter of the shaft was $6 \mathrm{~m}$. The vertical distance from the lower end of the connection between the wind tunnel and the shaft to the explosion-proof cover was $9.02 \mathrm{~m}$. The fan model of the installed main fan was ANN-2660/1440, with a total of 16 blades, and the installation angle of the fan blades was $45^{\circ}$. The vertical distance of the fan blade from the outer wall of the well was $16.44 \mathrm{~m}$. The geometric model is shown in Figures 1-3.

Ansys Fluent commercial software was used to numerically simulate the process of gas explosion wave propagation. The fan blades were static during the numerical simulation. The geometry model of wind shaft, wind tunnel, and explosionproof door was built and meshed by Ansys 17.2 Workbench. In the process of simulation and settlement, unstructured grid was used for the irregular areas such as wind tunnel and fan, and structural grid was used for the shaft area.

\subsection{Initial and Boundary Conditions}

\subsubsection{Initial Conditions}

(1) The initial pressure $P_{0}$ of the entire calculation area is $0 \mathrm{~Pa}$ relative to the atmospheric pressure

(2) The initial temperature $T_{0}$ is $298 \mathrm{~K}$

(3) The initial speed $V_{0}$ of the entire area is $0 \mathrm{~m} / \mathrm{s}$

(4) The entire area is filled with air

\subsubsection{Boundary Conditions}

(1) The outlet of the fan diffuser is set to pressure outlet, and the outlet pressure is set to $0 \mathrm{~Pa}$ relative to the atmospheric pressure.

(2) The bottom of the shaft is set to pressure inlet. Through the numerical simulation of the propagation process of the shock wave from the driving face along the return airflow to the shaft when the gas explosion occurred in the driving face, the distribution of the blast wave on the section of the shaft and the change rule with time under the condition of different gas explosion volume were obtained. The pressure distribution and time-varying rules are used as the boundary conditions of the inlet.

(3) Near wall surface used standard wall function.

The grid size and time step size have great influence on the results of numerical simulation. In order to verify the accuracy of the CFD model, grid independence analysis and time independence verification should be carried out [24-27]. The overpressure distribution on the fan blades is not uniform. The average overpressure on the blade is denoted as $P$, and the maximum value of $P$ with time is recorded as $P_{\max }$. The blade directly above the hub was chosen as the research object, and the changes of its $P_{\max }$ under different grid sizes and time steps were studied. In this paper, four grid numbers were conducted to verify the grid independence, including 4143528, 6617838, 8884708, and 12048764. The time independence verification was conducted for four time steps of $0.0005 \mathrm{~s}, 0.001 \mathrm{~s}, 0.005 \mathrm{~s}$, and $0.01 \mathrm{~s}$.

As we can see in Figure 4, with the increase of grid numbers, $P_{\max }$ increases gradually, but the increasing range decreases gradually. It can be assumed that the grid number of 6617838 reached grid independence. Therefore, in this paper, considering the computational efficiency, storage space, and accuracy, the grid number of 6617838 has been chosen as the calculation grid. It can be seen from Figure 5 that, as the time step decreases, $P_{\max }$ between time steps gets closer and closer. And considering the amount of calculation, the time step size was selected as $0.001 \mathrm{~s}$.

\section{Results and Discussion}

Blade 1 was directly above the hub. The shock wave generated by the gas with the concentration of $9.5 \%$ with a volume of $311.64 \mathrm{~m}^{3}$ propagated to the fan blade after the explosion of the driving face, and the distribution of shock wave overpressure on fan blades at different times was shown in Figure 6. It can be seen that when the shock wave propagated to the blades, the overpressure of 16 blades was not equal, and the change rule of the overpressure of 16 blades with time was basically the same.

3.1. Overpressure on Blades Changes with Time. The moment when overpressure starts to appear on the blades is recorded as $T_{1}$. The moment when $P_{\max }$ appears is recorded as $T_{2}$, and $T_{3}$ is the time interval between $T_{2}$ and $T_{1}$. The variation of $P$ on blades 1, 5, 9, and 13 with time is shown in Figure 7. Variation of $P$ on blades 1 with time under different gas explosion volume is shown in Figure 8.

It is not so hard to see from Figure 7 that occurrence time of overpressure and maximum overpressure time on each blade were basically the same. Figure 8 shows that $T_{1}$ and $T_{2}$ decrease with the increase of gas explosion volume. As the intensity of gas explosion increases, the width of the peak becomes narrower and narrower, that is, $T_{3}$ decreases as the volume of gas explosion increases. It is because that the shock wave generated by the larger gas explosion volume is stronger, and the shock wave speed is faster. The earlier the time $T_{1}$ on the fan blade, the earlier the time $T_{2}$ and the shorter the time interval $T_{3}$ between $T_{1}$ and $T_{2}$.

3.2. Maximum and Minimum Overpressure Blades. For different explosion gas volumes, when the gas explosion shock wave propagated to the fan blades, the maximum overpressure $P_{\max }$ experienced by each blade is shown in Figure 9. The maximum $P_{\max }$ of the 16 blades was recorded as $P_{m}$, and the minimum $P_{\max }$ was recorded as $P_{n}$. The $P_{m}$ value and $P_{n}$ value under different gas explosion volumes are shown in Table 1.

From Figure 9 and Table 1, it can be seen that $P_{\max }$ on each fan blade had little difference, blade 1 directly above the hub bore the maximum overpressure, and blade 9 directly 


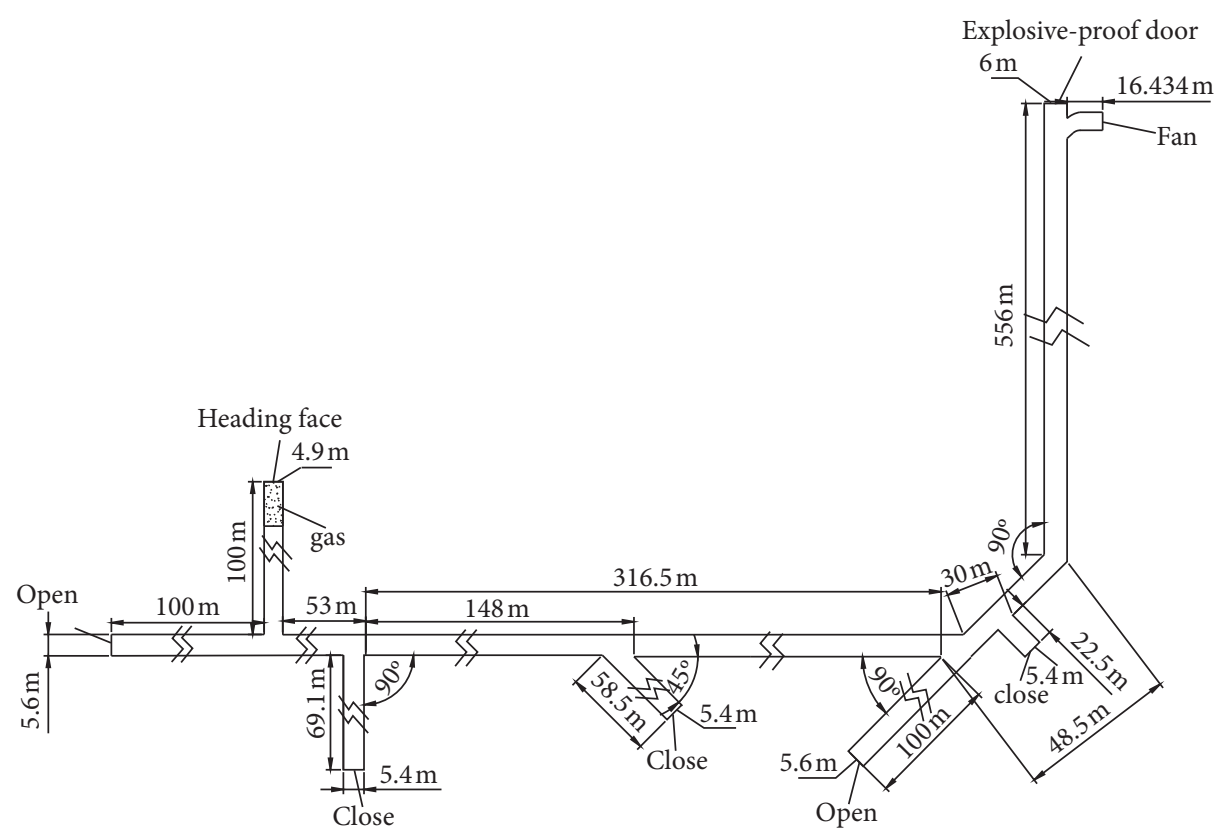

FIGURE 1: Geometric model of the heading face to the explosion-proof door and the wind shaft.

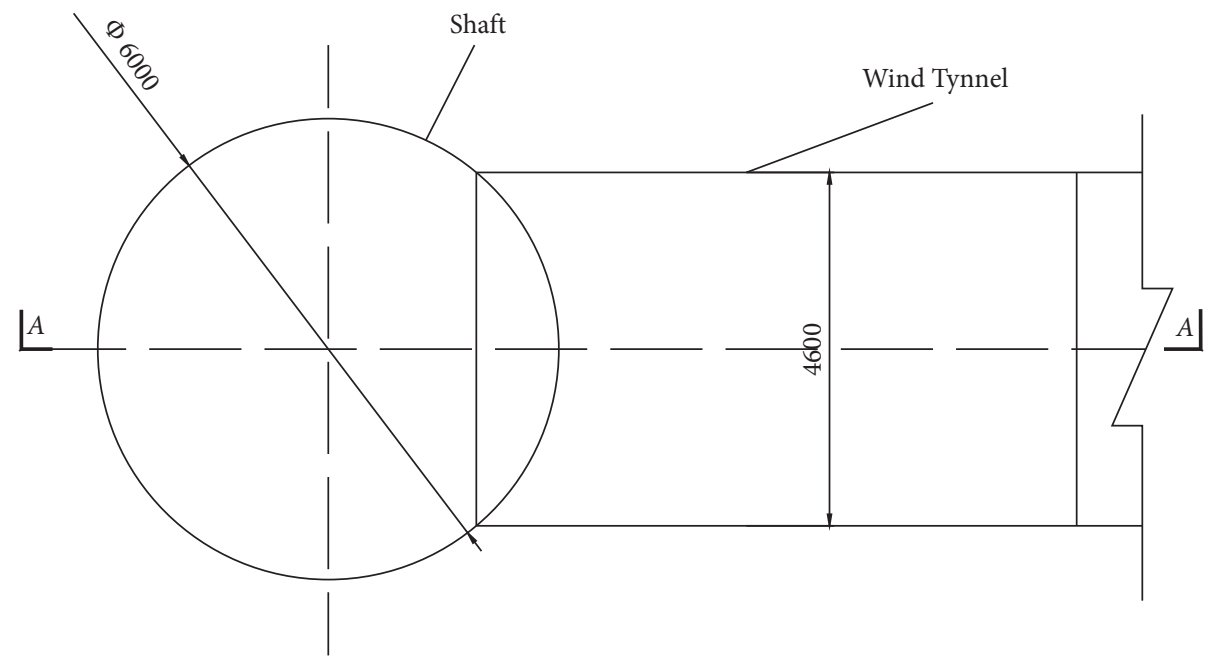

(a)

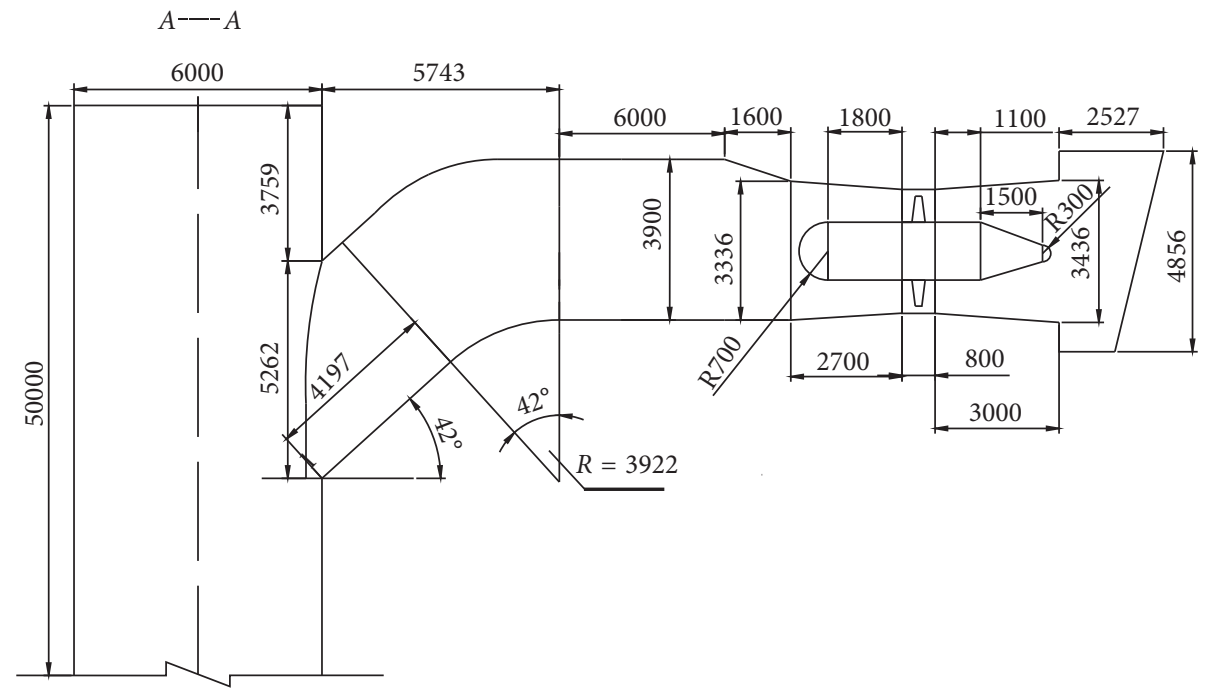

(b)

Figure 2: Geometric dimension of wind tunnel (unit: mm). (a). (b). 


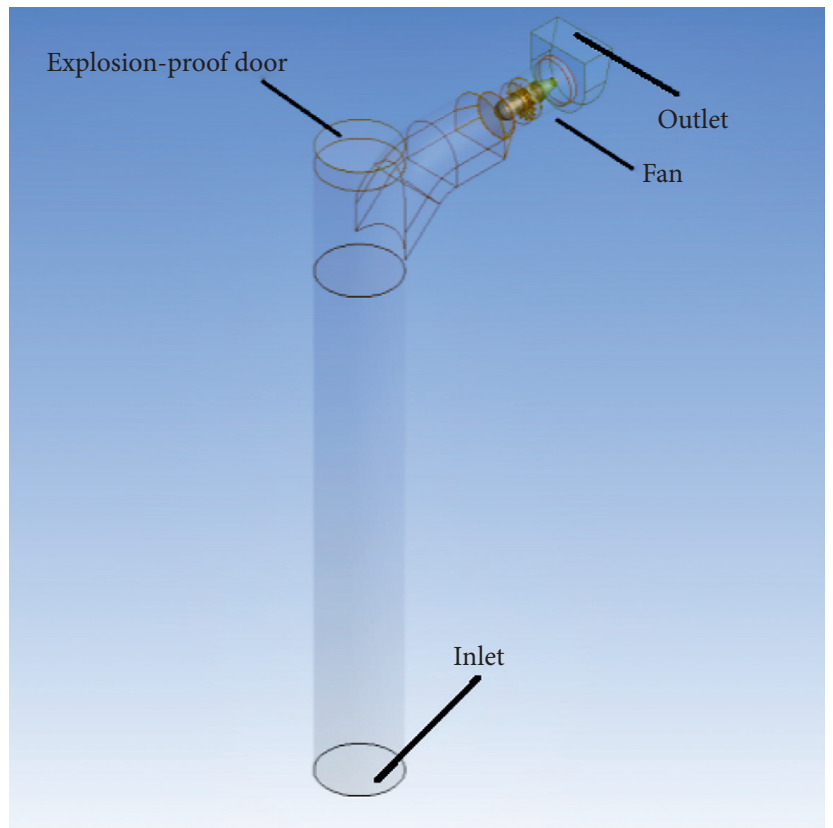

FIGURE 3: Schematic diagram of three-dimensional full-scale geometric model.

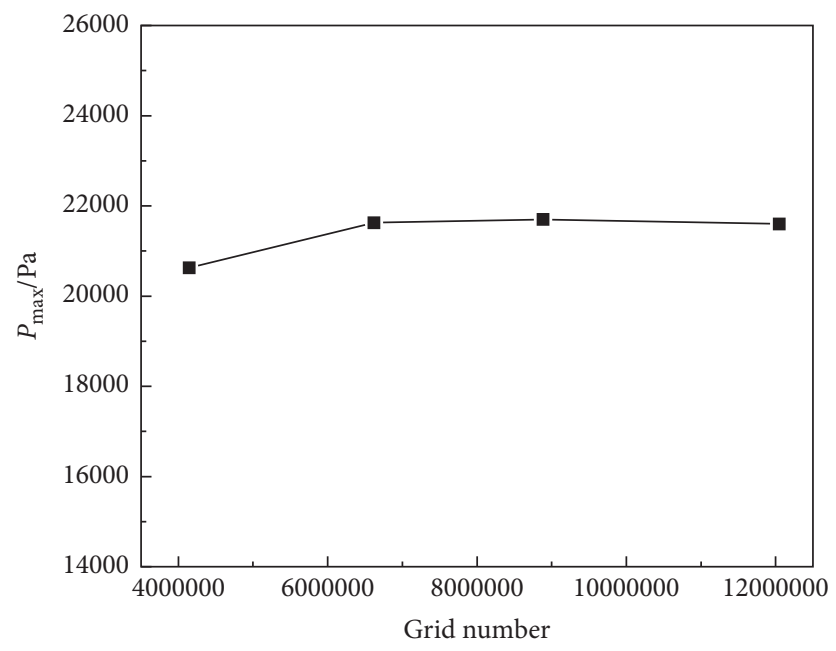

Figure 4: Grid independence verification diagram.

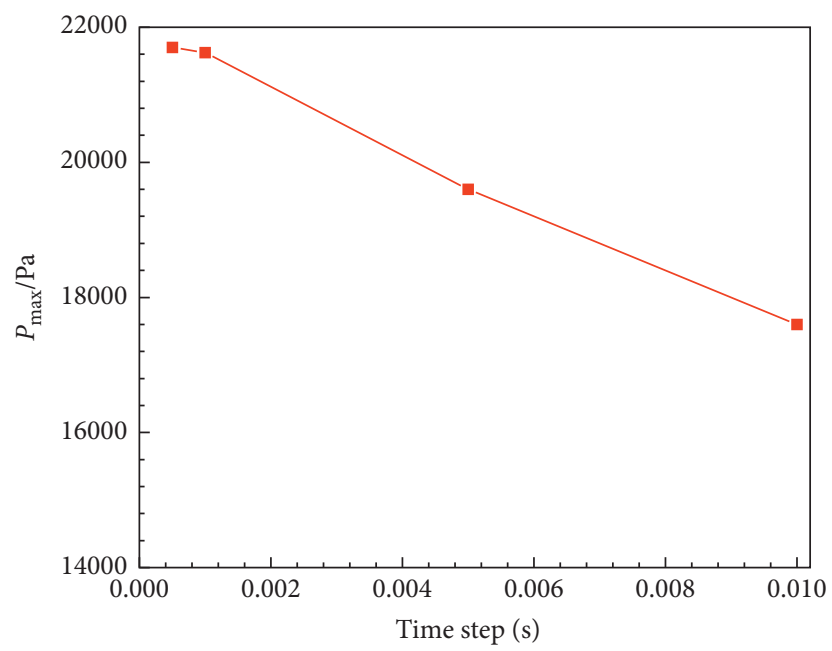

Figure 5: Time independence verification diagram. 


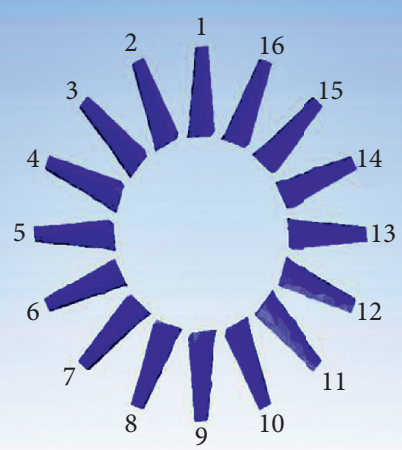

(a)

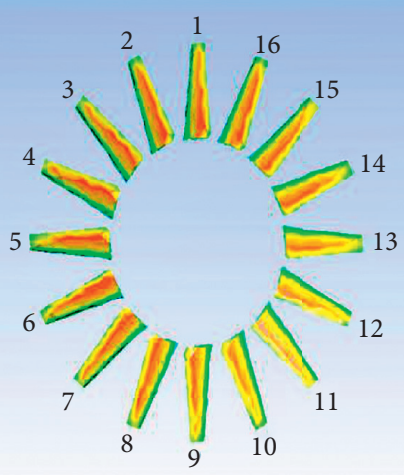

(c)

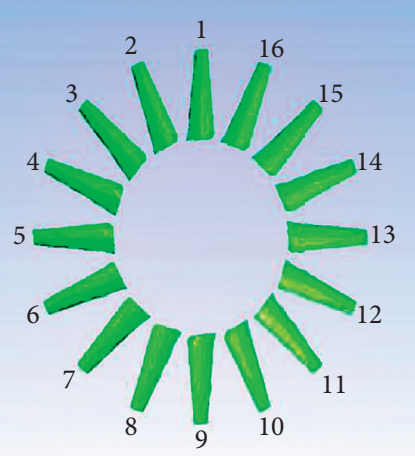

din

(b)

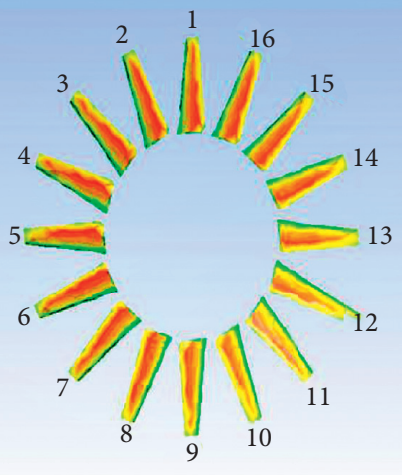

(d)

Figure 6: Cloud diagram of the overpressure change of the fan blade with time $\left(V=311.64 \mathrm{~m}^{3}\right)$. (a) $t=0 \mathrm{~m} \cdot \mathrm{s}$. (b) $t=153 \mathrm{~m} \cdot \mathrm{s}$. (c) $t=193 \mathrm{~m} \cdot \mathrm{s}$. (d) $t=204 \mathrm{~m} \cdot \mathrm{s}$.

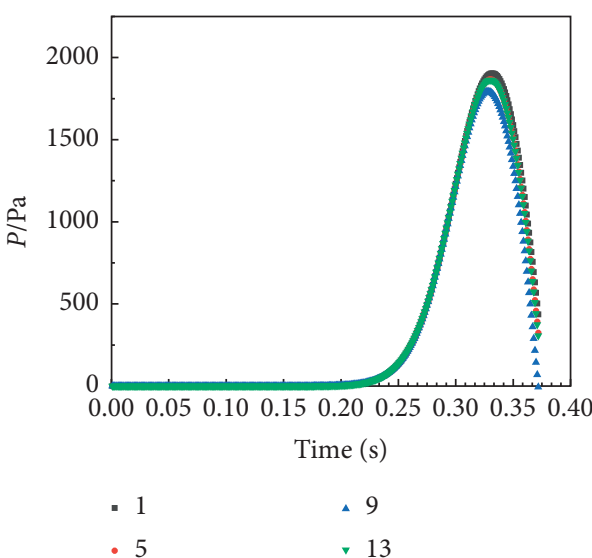

(a)

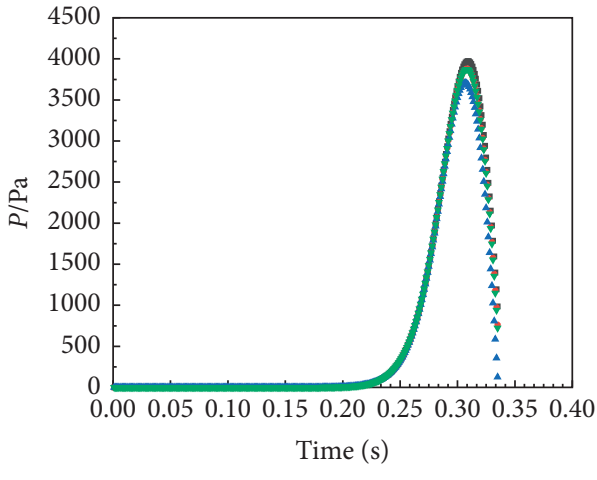

- 1

$\triangle 9$

$\checkmark 13$

(b)

Figure 7: Continued. 


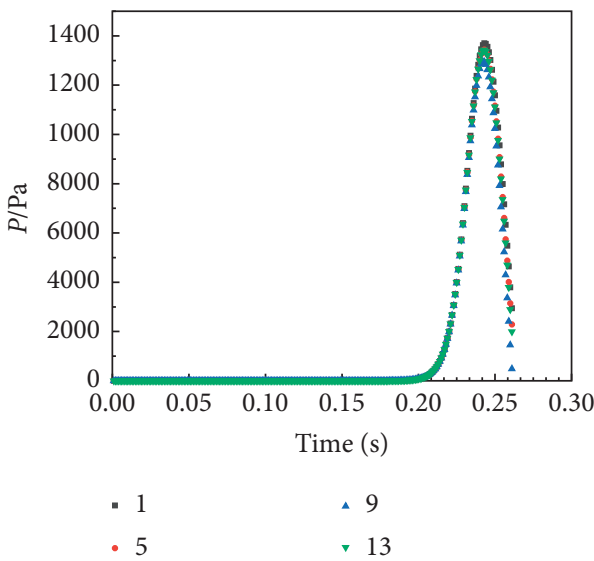

(c)

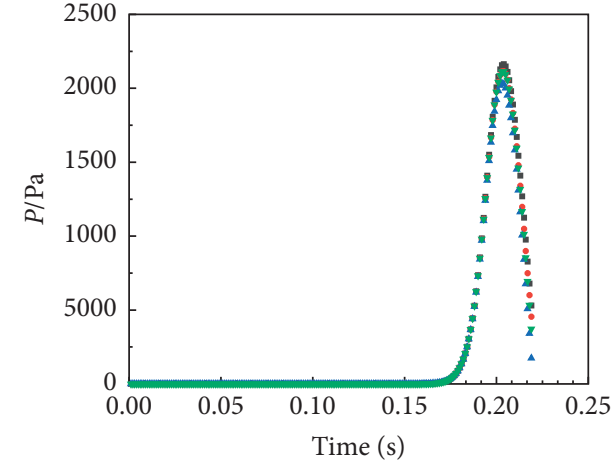

- 1

$\triangle 9$

- 13

(d)

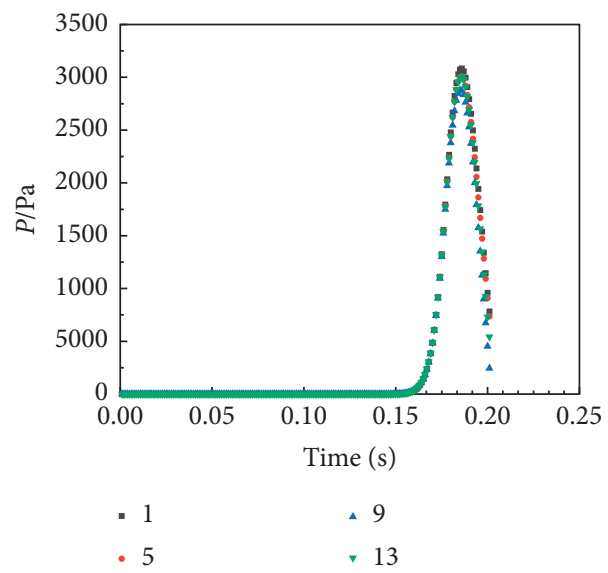

(e)

Figure 7: Variation of $P$ on blades $1,5,9$, and 13 with different gas explosion volumes over time. (a) Volume $=31.16 \mathrm{~m}^{3}$. (b) Volume $=62.33 \mathrm{~m}^{3}$. (c) Volume $=115.82 \mathrm{~m}^{3}$. (d) Volume $=311.64 \mathrm{~m}^{3}$. (e) Volume $=779.11 \mathrm{~m}^{3}$.

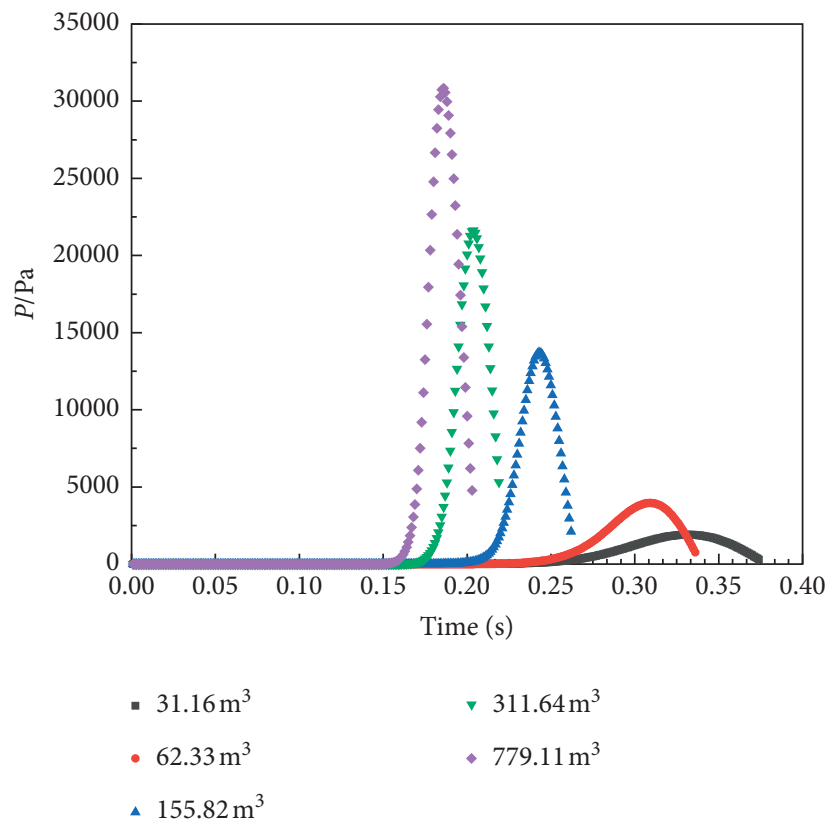

Figure 8: Time-varying graph of $P$ on blade 1 under different gas explosion volumes. 


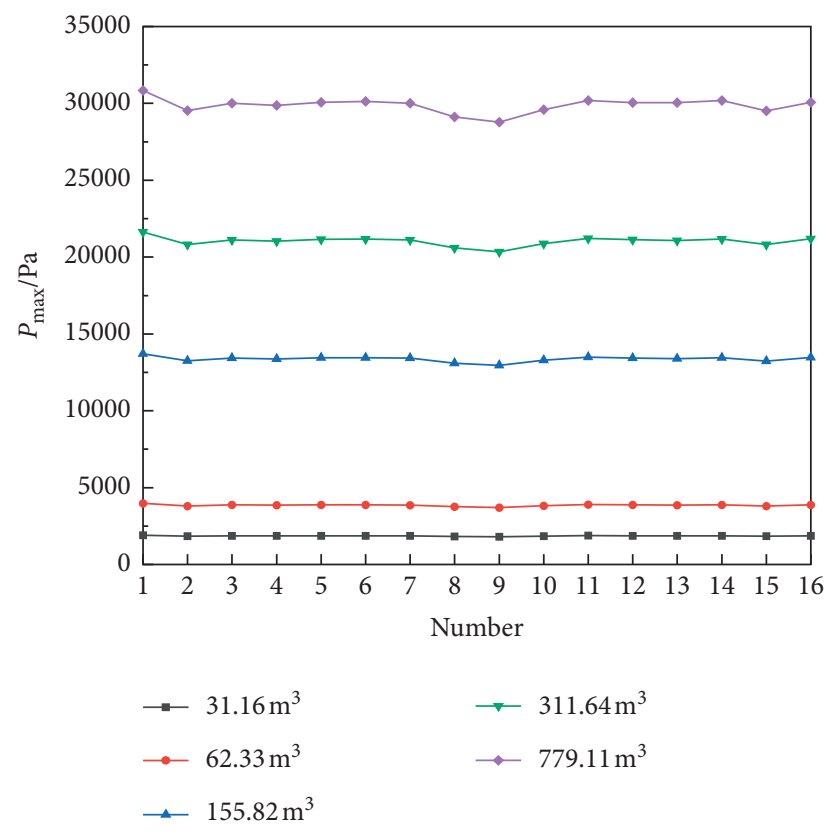

Figure 9: $P_{\max }$ on fan blades under different gas explosion volumes.

TABle 1: $P_{m}$ and $P_{n}$ under different gas explosion volumes.

\begin{tabular}{lccc}
\hline Gas explosion volume $\left(\mathrm{m}^{3}\right)$ & $P_{m}(\mathrm{~Pa})$ & $P_{n}(\mathrm{~Pa})$ & Difference $(\%)$ \\
\hline 33.16 & 1904 & 1794 & 5.78 \\
62.33 & 3973 & 3708 & 6.67 \\
155.82 & 13701 & 12955 & 5.44 \\
311.64 & 21626 & 20347 & 5.91 \\
779.11 & 30832 & 28781 & 6.65 \\
\hline
\end{tabular}

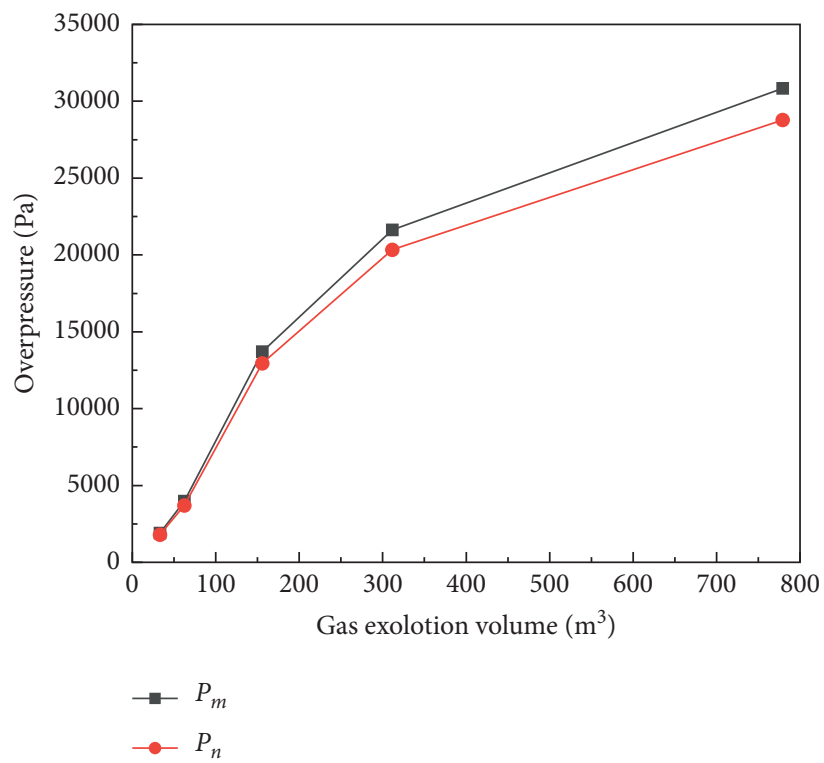

Figure 10: Relationship between $P_{m}$ and $P_{n}$ and gas explosion volume.

below the hub bore the minimum overpressure, which was caused by the change of the propagation direction of the shock wave in the wind tunnel. $P_{m}$ was $5.44-6.77 \%$ higher than $P_{n}$ under different explosion gas volumes.
The variation of $P_{m}$ and $P_{n}$ with explosion volume is shown in Figure 10. It can be seen that $P_{m}$ and $P_{n}$ increase with the increase of gas explosion volume, but the magnitude of the increase gradually decreases. 


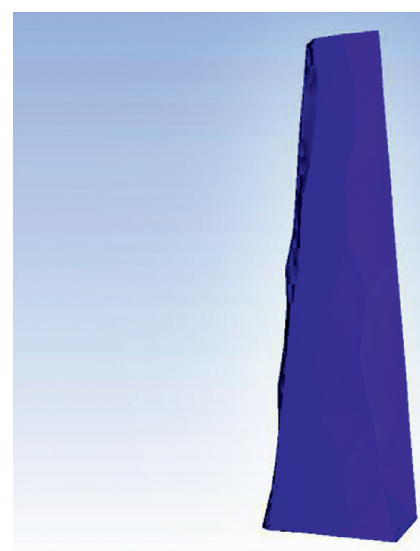

(a)

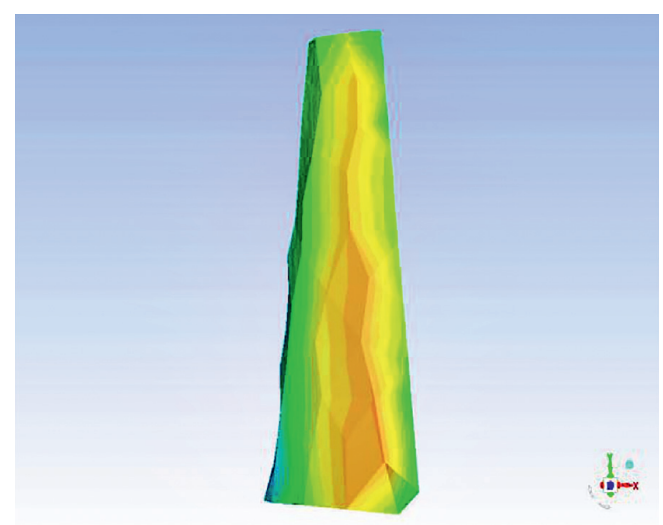

(c)

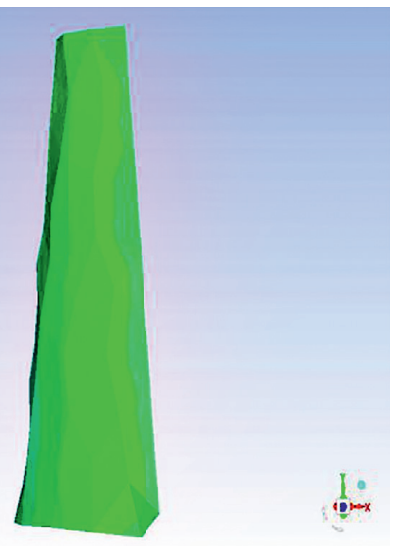

(b)

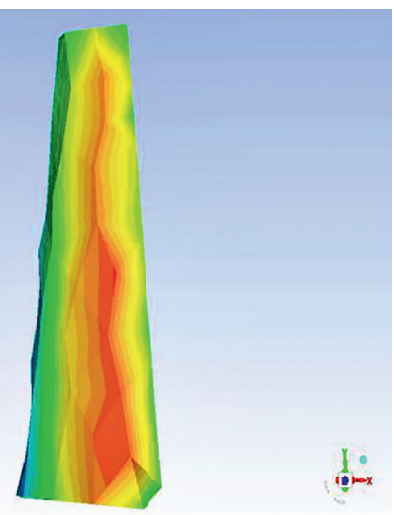

(d)

FIGURE 11: Cloud chart of pressure change with time of blade 1 when gas explosion volume was $311.64 \mathrm{~m}{ }^{3}$. (a) $t=0 \mathrm{~m} \cdot \mathrm{s}$. (b) $t=153 \mathrm{~m} \cdot \mathrm{s}$. (c) $t=193 \mathrm{~m} \cdot \mathrm{s}$. (d) $t=204 \mathrm{~m} \cdot \mathrm{s}$.
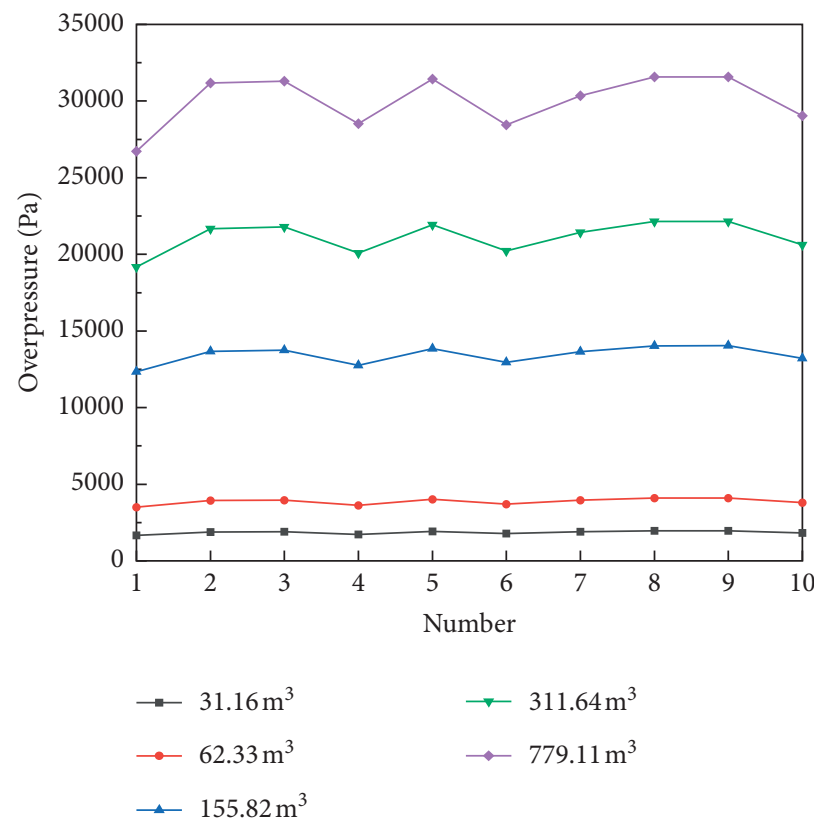

FIGURE 12: Overpressure distribution in the radial direction of blade 1 under different explosion volumes. 
TABle 2: $\mathrm{P}_{\mathrm{LM}}$ and $\mathrm{P}_{\mathrm{LN}}$ on blade 1 under different gas explosion volumes.

\begin{tabular}{lccc}
\hline Gas explosion volume $\left(\mathrm{m}^{3}\right)$ & $\begin{array}{c}\text { Maximum value } \\
(\mathrm{Pa})\end{array}$ & $\begin{array}{c}\text { Minimum value } \\
(\mathrm{Pa})\end{array}$ & Difference $(\%)$ \\
\hline 33.16 & 1968 & 1672 & 15.04 \\
62.33 & 4095 & 3496 & 14.63 \\
77.91 & 5606 & 4776 & 14.81 \\
155.82 & 14044 & 12350 & 12.06 \\
311.64 & 22154 & 19178 & 13.43 \\
779.11 & 31583 & 26720 & 15.40 \\
\hline
\end{tabular}

3.3. Distribution of Overpressure on the Blade. When the gas concentration was $9.5 \%$ and the explosion volume was $311.64 \mathrm{~m}^{3}$, the shock wave overpressure distribution at different moments on blade 1 located directly above the hub is shown in Figure 11. It can be seen that the distribution of overpressure on the blade was very uneven, and the blade edge bore the lowest overpressure and gradually increased from the edge to the inside.

The blade was divided into 10 segments from the root to the tip in the radial direction (the total length of the blade $H$ is $630 \mathrm{~mm}$, and the length of each segment $h$ is $63 \mathrm{~mm}$ ). The overpressure value of the segment with the highest overpressure was recorded as $P_{\mathrm{LM}}$, and the overpressure value of the segment with the lowest overpressure was recorded as $P_{\mathrm{LN}}$. When blade 1 reached $P_{\max }$, the distribution of the overpressure on the blade along the radial direction is shown in Figure 12, and $P_{\mathrm{LM}}$ and $P_{\mathrm{LN}}$ on the blade 1 under different gas explosion volumes are shown in Table 2.

Figure 12 showed that the overpressure on the fan blades showed a corrugated distribution in the radial direction, but the change range was not large. From Table 2, it can be seen that, under different gas explosion volumes, the overpressure value $P_{\mathrm{LM}}$ of the segment with the largest overpressure in the radial direction of the fan blade was $12.06 \%$ to $15.40 \%$ greater than the overpressure value $P_{\mathrm{LN}}$ of the segment with the least overpressure.

\section{Conclusion}

In this paper, we took Yangchangwan No. 2 return air well as the research object. When the gas explosion occurred in the driving face, the propagation process of the explosion shock wave in the shaft and the air tunnel under different gas explosion volume conditions and the dynamic process of the main fan blades under the impact load were simulated numerically. The overpressure on the blade at different times, the overpressure distribution on the blade, and the relationship between the overpressure and the explosion intensity were obtained, which can be used as a reference for the structural design of fans.

(a) $T_{1}$ and $T_{2}$ on each blade were basically the same. With the increase of gas explosion volume, the time when the overpressure appeared on the fan blade was advanced, and the time to reach the maximum overpressure was also advanced. The time interval $T_{3}$ between $T_{1}$ and $T_{2}$ decreased.

(b) There is little difference in overpressure on each blade because of the different angle between the fan blades and the direction of shock wave. The fan blade directly above the hub was subject to the highest overpressure, and directly below the hub was subject to the lowest overpressure. The overpressure of the maximum overpressure blade was $5.44 \%$ to $6.77 \%$ higher than that of the minimum overpressure blade.

(c) The distribution of overpressure on each fan blade was uneven, and the overpressures on blade edges were the lowest. The overpressure gradually increased from the edge to the inside. The overpressure on the fan blades showed a corrugated distribution in the radial direction. The overpressure value of the maximum overpressure sections of the fan blade was $12.06 \%$ to $15.40 \%$ larger than the minimum overpressure sections.

\section{Data Availability}

All the data used to support the findings of this study are available from the corresponding author upon request.

\section{Conflicts of Interest}

The authors declare that there are no conflicts of interest regarding the publication of this paper.

\section{Acknowledgments}

This work was supported by the National key R \& D plan program of China (no. 2018YFC0808103), National Natural Science Foundation of China (Grant nos. 52074106, 51734007, and 51704099) Key Scientific Research Projects in Colleges and Universities in Henan (Grant no. 19A440003), the Doctoral Fund of Henan Polytechnic University (Grant no. B2019-56), and the Fundamental Research Funds for the Universities of Henan Province (Grant no. NSFRF180338).

\section{References}

[1] D. A. Kessler, V. N. Gamezo, and E. S. Oran, "Simulations of flame acceleration and deflagration-to-detonation transitions in methane-air systems," Combustion and Flame, vol. 157, no. 11, pp. 2063-2077, 2010.

[2] M. S. Kuznetsov, V. I. Alekseev, and S. B. Dorofeev, "Comparison of critical conditions for DDT in regular and irregular cellular detonation systems," Shock Waves, vol. 10, no. 3, pp. 217-223, 2000.

[3] T. Obara, S. Yajima, T. Yoshihashi, and S. Ohyagi, "A highspeed photographic study of the transition from deflagration 
to detonation wave," Shock Waves, vol. 6, no. 4, pp. 205-210, 1996.

[4] O. Peraldi, R. Knystautas, and J. H. Lee, "Criteria for transition to detonation in tubes," in Proceedings of Twenty-first Symposium (International) on Combustion, vol. 21, pp. 1629-1637, Seattle, WA, USA, August 1988.

[5] M. I. Radulescu, G. J. Sharpe, J. H. S. Lee, C. B. Kiyanda, A. J. Higgins, and R. K. Hanson, "The ignition mechanism in irregular structure gaseous detonations," in Proceedings of the Combustion Institute, vol. 30, pp. 1859-1867, Elsevier Ltd., UK, January 2005.

[6] J. Xu, S. Xu, and G. Yang, "Experimental study on mine gas explosion diffusion," Coal Science and Technology, vol. 32, no. 7, pp. 55-57, 2004.

[7] W. Zhang, F. He, L. Cheng, X. Song, and G. Yang, "Wire congestion estimation in a bounded-bend model," International Journal of Electronics, vol. 97, no. 11, pp. 1263-1281, 2010.

[8] Q. Zhang, B. Qin, and D.-C. Lin, "Estimation of pressure distribution for shock wave through the junction of branch gallery," Safety Science, vol. 57, pp. 214-222, 2013.

[9] W. Hou, Z. M. Qu, and L. J. Pian, "Numerical simulation on propagation and attenuation of shock waves in simplex turn roadway during gas explosion," Journal of China Coal Society, vol. 34, pp. 667-672, 2009.

[10] Z. W. Jia, Y. W. Liu, and G. X. Jing, "Propagation characteristic about shock wave of gas explosion at laneway corner," Journal of China Coal Society, vol. 36, pp. 97-100, 2009.

[11] B. Lin, Q. Ye, and Z. Cheng, "Propagation law and analysis of gas explosion in bifurcated pipeline," Journal of China Coal Society, vol. 33, no. 2, pp. 136-139, 2008.

[12] B. Lin and C. Kan, "Characteristics of energy variation and wall thermal effect of blast wave," Journal of China Coal Society, vol. 29, no. 4, pp. 429-433, 2004.

[13] Z. Cheng, B. Lin, C. Kan et al., "Influence of wall roughness on flame wave propagation of gas explosion," Journal of China University of Mining and Technology, vol. 35, no. 1, pp. 39-43, 2006.

[14] C.-J. Zhu, Z.-S. Gao, B.-Q. Lin et al., "The effect of bend positions on premixed methane-air explosion overpressures in ducts," International Journal of Spray and Combustion Dynamics, vol. 8, no. 4, pp. 254-261, 2016.

[15] R. Blanchard, D. Arndt, R. Grätz, M. Poli, and S. Scheider, "Explosions in closed pipes containing baffles and 90 degree bends," Journal of Loss Prevention in the Process Industries, vol. 23, no. 2, pp. 253-259, 2010.

[16] Q. Ma, Q. Zhang, and J. Chen, "Numerical analysis on propagation characteristics of methane/air explosion in elbow pipe and pipe network," International Journal of Numerical Methods for Heat \& Fluid Flow, vol. 24, no. 7, pp. 1610-1623, 2014.

[17] B. E. Gel'fand, S. P. Medvedev, and S. M. Frolov, "Interaction of air shocks with a rigid wall protected by an extended screen," Fluid Dynamics, vol. 26, no. 1, pp. 153-156, 1991.

[18] P. Kosinski, "On shock wave propagation in a branched channel with particles," Shock Waves, vol. 15, no. 1, pp. 13-20, 2006.

[19] A. Kobiera, J. Kindracki, P. Zydak, and P. Wolanski, "A new phenomenological model of gas explosion based on characteristics of flame surface," Journal of Loss Prevention in the Process Industries, vol. 20, no. 3, pp. 271-280, 2007.

[20] C. G. Thom and D. S. Cronin, "Shock wave amplification by fabric materials," Shock Waves, vol. 19, no. 1, pp. 39-48, 2009.
[21] Q. Zhang, L. Pang, and H. M. Liang, "Effect of scale on the explosion of methane in air and its shockwave," Journal of Loss Prevention in the Process Industries, vol. 24, no. 1, pp. 43-48, 2011.

[22] Q. Zhang, L. Pang, and S. X. Zhang, "Effect of scale on flame speeds of methane-air," Journal of Loss Prevention in the Process Industries, vol. 24, no. 5, pp. 705-712, 2011.

[23] H. Zhian, L. Zhigang, C. Shengguo, Z. Yansong, and Z. Yinghua, "Numerical simulation and study on the transmission law of flame and pressure wave of pipeline gas explosion," Safety Science, vol. 50, no. 4, pp. 806-810, 2012.

[24] E. B. Liu, W. S. Li, H. J. Cai, and S. B. Peng, "Formation mechanism of trailing oil in product oil pipeline," Processes, vol. 7, no. 1, p. 7, 2019.

[25] Z. Su, E. Liu, Y. Xu, P. Xie, C. Shang, and Q. Zhu, "Flow field and noise characteristics of manifold in natural gas transportation station," Oil \& Gas Science and Technology-Revue D'IFP Energies Nouvelles, vol. 74, p. 70, 2019.

[26] S. Peng, Q. Chen, C. Zheng, and E. Liu, "Analysis of particle deposition in a new-type rectifying plate system during shale gas extraction," Energy Science \& Engineering, vol. 8, no. 3, pp. 702-717, 2020.

[27] Z. Zhao, M. Zhang, Q. Ma, and B. Chen, "Deviation effect of coaxiality on the rock Brazilian split," Advances in Mathematical Physics, vol. 2020, p. 8, Article ID 5782457, 2020. 